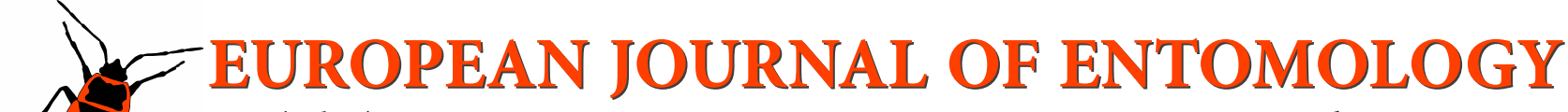 \\ ISSN (online): 1802-8829 \\ http://www.eje.cz \\ Eur. J. Entomol. 113: 99-103, 2016 \\ doi: 10.14411/eje.2016.012 \\ ORIGINAL ARTICLE
}

\section{Influence of natal host on parasitism by Spalangia cameroni (Hymenoptera: Pteromalidae)}

\author{
Francisco Beitia1', Erik VAlenCiA¹, Bernat PERIS ${ }^{2}$, Luis DE PEDRO ${ }^{1,3}$, Josep D. ASíS ${ }^{3}$ and José TORMOS ${ }^{3}$ \\ ${ }^{1}$ Instituto Valenciano de Investigaciones Agrarias, Unidad Asociada de Entomología IVIA/CIB-CSIC, Apartado Oficial, \\ 46113-Montcada, Spain; e-mails: beitia_fra@gva.es, eriksandor.valencia@campus.uab.es, peris_berpal@gva.es \\ ${ }^{2}$ Departamento de Ciencia Animal, E.T.S de Ingeniería Agronómica y del Medio Natural, Universidad Politécnica de Valencia, \\ 46022-Valencia, Spain; e-mail: peris_berpal@gva.es \\ ${ }^{3}$ Universidad de Salamanca, Facultad de Biología, Unidad de Zoología, Campus Miguel de Unamuno, 37007-Salamanca, \\ Spain; e-mails: asis@usal.es, tormos@usal.es
}

Key words. Hymenoptera, Pteromalidae, Spalangia cameroni, Diptera, Tephritidae, Muscidae, rearing protocol, animal welfare

\begin{abstract}
Spalangia cameroni Perkins (Hymenoptera: Pteromalidae) is sold commercially as a biocontrol agent of filth flies, including the house fly, Musca domestica L. (Diptera: Muscidae). For this reason, S. cameroni is mass-reared for inundative releases to control harmful flies. However, the mass-rearing protocols include very little information on the influence of natal host on subsequent host selection by parasitoids with more than one potential host as in the genus Spalangia. Here, we report on the use of $S$. cameroni against $M$. domestica. The S. cameroni were reared using Ceratitis capitata Wiedemann (Diptera: Tephritidae) (natal host) pupae for several generations. Freeze-killed fly pupae were used in assays to determine the fecundity, number of adult progeny and sex-ratio of this parasitoid. Realized fecundity and number of adult progeny were greater when provided with house fly pupae than Mediterranean fruit fly pupae. Thus $S$. cameroni parasitized more house fly pupae than $C$. capitata pupae, even though the parasitoid was reared on Mediterranean fruit fly for many generations. These results indicate that $S$. cameroni reared on C. capitata can be successfully used in inundative releases against both fruit flies (agriculture) and house flies (livestock farming).
\end{abstract}

\section{INTRODUCTION}

At the Valencian Institute of Agrarian Research (Instituto Valenciano de Investigaciones Agrarias, IVIA, Valencia, Spain) Spalangia cameroni Perkins (Hymenoptera: Pteromalidae) has been reared for use in biological control against the Mediterranean fruit fly since 2003. During this time the Medfly Ceratitis capitata (Wiedemann) was used as the host (Tormos et al., 2010, 2014). Recently, we decided to use $S$. cameroni to control Diptera that are common pests of feedlot cattle and in animal breeding facilities, such as Musca domestica L. and the stable fly, Stomoxys calcitrans (L.) (Diptera: Muscidae).

In biological control, the host used for rearing parasitoids is important as according to Hopkins' Host-Selection Principle it may influence their subsequent choice of host and percentage parasitism (Davis \& Stamps, 2004). Currently, little is known about conditioning and host selection in parasitoids of muscoid flies, but in other species the host in which the female parasitoid is reared has a significant effect on their host-seeking behaviour and oviposition (Ferrero, 2008). In this study, therefore, we determined wheth- er S. cameroni reared on C. capitata for many generations would parasitize $M$. domestica.

Cyclorrhaphous Diptera are pests and a major cause of discomfort to livestock in the province of Valencia (Spain), particularly house and stable flies (authors' pers. observ.). Farmers commonly control these pests as they can reach high densities in summer on livestock and poultry farms, causing discomfort to animals, workers and nearby residents. Furthermore, they can be carriers of bacteria and viruses (Abrams, 1976; Milushev, 1978; Rosef \& Kapperud, 1983; Chakrabarti et al., 2008; Wanaratana et al., 2013), infections with which can also cause economic losses. In addition, the painful bite of the stable fly lowers milk production and causes animal weight loss (Bruce \& Decker, 1958; Campbell et al., 1987).

Traditionally, farmers have used insecticides to control these insects, but have started to use alternative methods of control over the last 30 years (e.g. biological control sensu stricto), mainly due to the risk posed by the residues of the insecticides in animal products and manure (Skovgård, 2006; Birkemoe et al., 2009), as well as the fact that flies rapidly become resistant to them. 
S. cameroni is one of the most commonly used parasitoids in the biological control of the house fly, M. domesti$c a$, and stable fly, $S$. calcitrans (pest of equine facilities, see Machtinger \& Geden, 2015). Inundative releases of several species of Spalangia are now being used in several countries. Under some conditions, these releases have resulted in levels of parasitism sufficient to control populations of these flies and keep them below economic thresholds (Morgan \& Patterson, 1990; Geden et al., 1992; Crespo et al., 1998; Kaufmann et al., 2001; Steenberg et al., 2001; Skovgård \& Nachman, 2004; Geden \& Hogsette, 2006).

Currently there is information that supports the effectiveness of using parasitoids, in particular $S$. cameroni, to control harmful flies on farms. Consequently S. cameroni, reared on house-fly pupae (Kaufman \& Geden, 2009) are used against filth flies in several countries. In this study we reared S. cameroni on C. capitata with the following objective: to assess the potential use of $S$. cameroni reared on $C$. capitata to control M. domestica.

\section{MATERIALS AND METHODS}

\section{Study center and insects*}

This study was carried out at the Valencian Institute of Agrarian Research (IVIA, Valencia, Spain). Freeze-killed host pupae were used because previous studies indicate these pupae are suitable hosts for $S$. cameroni (Tormos et al., 2010; Ogawa et al., 2012). Pupae of the Mediterranean fruit fly and adults of $S$. cameroni were obtained from cultures reared following the standard protocol used at IVIA, where they have been reared for over 6 years. The laboratory conditions were $21-24^{\circ} \mathrm{C}$, RH $55-80 \%$ and a 16L : 8D photoperiod. Live pupae of the house fly provided by BioFlyTech UA (Alicante, Spain) were used to determine the minimum time it took house fly pupae to die at $-20^{\circ} \mathrm{C}$. The time required to kill Mediterranean fruit fly pupae at $-20^{\circ} \mathrm{C}$ was previously determined by Tormos et al. (2010). Both Mediterranean fruit fly and house fly pupae used in the experiments were 2 day old when freeze killed. In both cases, after being frozen, they were stored at $4-5^{\circ} \mathrm{C}$ for a period of 6-7 days prior to being confined with parasitoids for $24 \mathrm{~h}$.

\section{Experimental design}

To determine the minimum time necessary to kill house fly pupae by freezing them, 2-day-old pupae were divided into 5 groups each of 65 pupae, each group of which was placed in a glass Petri dish $(5 \times 2 \mathrm{~cm})$. The pupae were exposed to $-20^{\circ} \mathrm{C}$ for $15,30,60,90$ or $120 \mathrm{~min}$ (Table 1 ). The age of the pupae, temperature, duration of exposure and number of repetitions was based on previous experiments using other hosts of $S$. cameroni (Geden $\&$ Kaufman, 2007; Tormos et al., 2010, 2014). The treated pupae were then transferred to a climatic chamber at $25 \pm 1^{\circ} \mathrm{C}$, RH 55 $85 \%$ and a $16 \mathrm{~L}: 8 \mathrm{D}$ photoperiod. Untreated pupae $(\mathrm{n}=65)$, were also placed in the climatic chamber and used as controls.

The effect of host species (C. capitata or M. domestica) on the reproductive behaviour of the parasitoid was recorded in two treatments performed simultaneously (Fig. 1). Each treatment consisted of three replicates in each of which 30 pairs of parasitoids were confined individually in a container with a Petri dish containing pupae (90 in total). In each container (transparent plastic, $15 \mathrm{~cm}$ length $\times 10$ width $\times 10$ height) there was an uncovered Petri dish base $(\varnothing 3 \mathrm{~cm})$ containing a group of host pupae, a Petri dish top containing sugar, a bowl of water, blotting paper impreg-

\footnotetext{
* Experiments comply with current Spanish legislation.
}

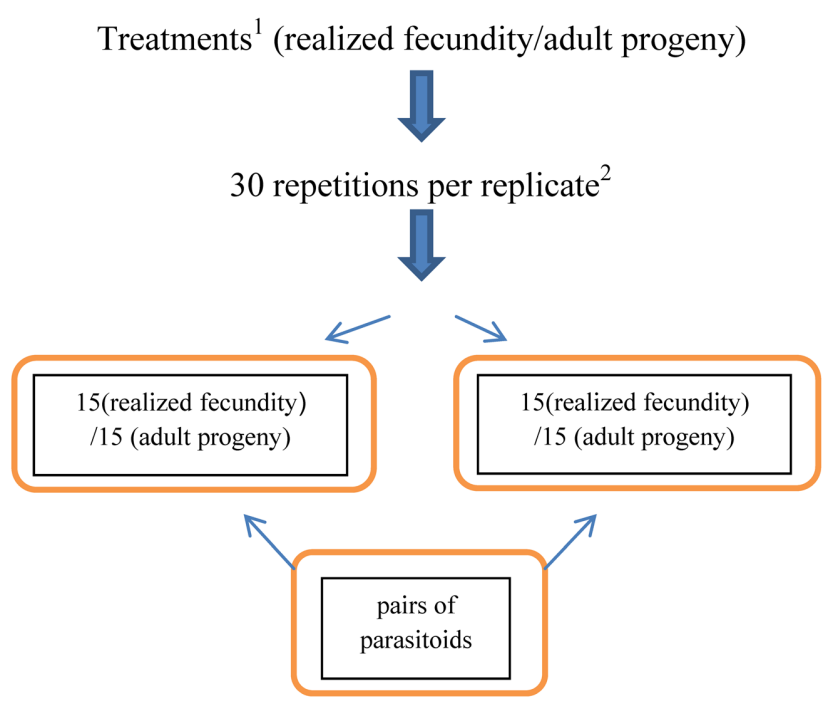

10 pupae x 24 hours x 3 exposures per week ${ }^{3}$

Fig. 1. Protocol followed in order to determine the effect of host species on parasitoid reproduction. ${ }^{1}$ Two identical treatments, only differing in host species ( $M$. domestica / C. capitata). Three replicates per treatment. ${ }^{2}$ Repetition: In each repetition an uncovered Petri dish base $(3 \times 3 \mathrm{~cm})$ was placed inside a transparent plastic container with 10 host pupae, sugar, water, honey and a pair (male and female) of parasitoids. ${ }^{3}$ Protocol: There were 30 containers, each with 10 pupae killed by freezing, sugar, water and "honeypaper". A pair of 4-5 day-old parasitoids was added to each box, where they remained in contact with the pupae for $24 \mathrm{~h}$, after which the pupae were changed. Each pair was confined with pupae three times per week, which constituted a replicate. The pairs of parasitoids were only used in one replicate. This was repeated three times with each host species.

nated with honey and a pair (male and female) of 4-5 day-old parasitoids, which had been kept together since their emergence. Each treatment lasted for 3 consecutive weeks and, therefore, each replicate lasted one week. At the beginning of each week, each pair of parasitoids was confined with 10 host pupae for $24 \mathrm{~h}$ on three occasions over the course of a week. Different pairs of parasitoids were used in each replicate. At the end of each week we determined the total number of eggs laid per female (realized fecundity), total number of adult offspring produced per female (adult progeny), incidence of superparasitism (presence of $>1$ egg per pupa) and sex ratio. In order to determine realized fecundity and superparasitism, 450 pupae from each treatment were dissected under a binocular microscope (Leica MZ8), with the aid of mounted needles and soft tweezers (Tormos et al., 2009). The remaining 450 pupae of each treatment were allowed to develop in order to determine the number of adult progeny that emerged

Table 1. Mortality of approximately 2 -day-old house fly pupae exposed to $-20^{\circ} \mathrm{C}$ for different lengths of time [12.04.13 (exposure) / 17.04.13 (onset of emergence of adult flies)]. They were previously kept on Petri dishes in a climatic chamber [Sanyo MLR350 $21-26^{\circ} \mathrm{C}, \mathrm{RH} 55-85 \%, 16 \mathrm{~L}$ : 8D photoperiod]. For each exposure time, 8 pupae were used as controls, from all which adult flies emerged.

\begin{tabular}{ccc}
\hline $\begin{array}{c}\text { Exposure time } \\
\text { (min) }\end{array}$ & $\begin{array}{c}\text { Emerging adults/ } \\
\text { pupae exposed }\end{array}$ & Mortality (\%) \\
\hline 15 & $62 / 65$ & $4.62 \%$ \\
30 & $18 / 65$ & $72.31 \%$ \\
60 & $3 / 65$ & $95.39 \%$ \\
90 & $2 / 65$ & $96.93 \%$ \\
120 & $0 / 65$ & $100.00 \%$ \\
\hline
\end{tabular}


Table 2. Realized fecundity, number of pupae parasitized, incidence of superparasitism, number of adult progeny and proportion that were females when S. cameroni was allowed to parasitize C. capitata and M. domestica, over a period of 6-7 days ( $\mathrm{n}=45$ ) (there was no difference between weeks).

\begin{tabular}{|c|c|c|c|c|c|c|}
\hline & \multicolumn{3}{|c|}{ C. capitata } & \multicolumn{3}{|c|}{ M. domestica } \\
\hline & Range & Mean & SE & Range & Mean & SE \\
\hline Realized fecundity & $0-24$ & 6.52 & 6.88 & $4-20$ & 11.82 & 3.61 \\
\hline Number of pupae parasitized & $0-11$ & 5 & 4.56 & $4-14$ & 9 & 2.60 \\
\hline Incidence of superparasitism & $0-4$ & 0.85 & 1.23 & $0-6$ & 1.92 & 1.47 \\
\hline Adult progeny & $0-4$ & 0.92 & 1.37 & $0-7$ & 3.18 & 1.91 \\
\hline Proportion female & $0-7$ & 1.05 & 1.96 & $0-9$ & 3.64 & 2.51 \\
\hline
\end{tabular}

and their sex ratio. Throughout this study, the containers were kept in a Sanyo climatic chamber (MLR350; Sartorius, Barcelona, Spain) at $24 \pm 1{ }^{\circ} \mathrm{C}, 55-65 \%$ relative humidity and a photoperiod of $16 \mathrm{~h}$ per day.

\section{Statistical tests and analyses}

A two-way factorial ANOVA was used to test the effect of the fixed factor: Mediterranean fruit fly pupa/house fly pupa, and a random factor: time period (week) in which the pairs of parasitoids were kept with pupae on the variables: (1) realized fecundity; (2) number of pupae parasitized; (3) superparasitism; (4) number of adult progeny and (5) proportion that were females. Chi squared tests $\left(\chi^{2}\right)$ was also used to analyze the sex-ratios. Values are reported as means $\pm \mathrm{SE}$. Analyses were performed using the IBM SPSS statistical software package (IBM, Spain; v20; critical $p$ value used 0.05).

\section{RESULTS}

Temperature and minimum exposure time resulting in $100 \%$ mortality of $M$. domestica pupae was $-20^{\circ} \mathrm{C}$ for 120 min (Table 1).

The two-way ANOVA $\left[\sigma^{2}\right.$ (residual variance): $31.02, \sigma_{B}^{2}$ (block variance): $4 \times 10^{-5}$ ] revealed that the realized fecundity of $S$. cameroni differed significantly for the two hosts $\left(F_{1,28}=6.62 ; P=0.01\right)$, being higher when parasitizing $M$. domestica than $C$. capitata (Table 2). Number of pupae parasitized and superparasitism were lower when parasitizing Mediterranean fruit flies than house flies (twoway ANOVA $\left[\sigma^{2}\right.$ (residual variance): $13.69, \sigma_{B}^{2}$ (block variance): 0.12$\left.] F_{1,28}=8.93 ; p=0.005\right)$, (two-way ANOVA $\left[\sigma^{2}\right.$ (residual variance): $1.88, \sigma_{B}^{2}$ (block variance): $6.9 \times 10^{-5}$ ] $\left.F_{1,28}=4.42 ; p=0.04\right)$. More adult progeny and a greater proportion of females emerged from house flies than from Mediterranean fruit flies (two-way ANOVA $\left[\sigma^{2}\right.$ (residual variance): $11.36, \sigma_{B}^{2}$ (block variance): 0.10$] F_{1,28}=15.53 ; p$ $=0.0001)$; (two-way ANOVA [ $\sigma^{2}$ (residual variance): 5.15 , $\sigma_{B}^{2}$ (block variance): $\left.4.8 \times 10^{-5}\right] F_{1,28}=9,82 ; p=0.004$ ) . The sex ratio of the adults that emerged from Mediterranean fruit fly and house fly pupae did not differ significantly $\left(\chi^{2}=1.02, d f 1, P=0.306\right)$.

\section{DISCUSSION AND CONCLUSIONS}

It is reported that the pupae of $M$. domestica are killed if kept at $-80^{\circ} \mathrm{C}$ for 10 min (Geden \& Kaufman, 2007) and those of $C$. capitata if kept at $-20^{\circ} \mathrm{C}$ for $60 \mathrm{~min}$ (Tormos et al., 2010).

$S$. cameroni is an idiobiont pupal parasitoid with a broad range of dipterous hosts, harmful to both crops and livestock (Birkemoe et al., 2009; Tormos et al., 2014). Consequently, since 2006, when $S$. cameroni was first identified as a parasitoid of $C$. capitata (Falcó et al., 2006), the Valencian Institute for Agricultural Research (IVIA) in Spain started rearing $S$. cameroni on $C$. capitata for controlling the Mediterranean fruit fly. This parasitoid continued to be bred on the fruit fly pupae for the following reasons: (a) according to Hopkins' Host-Selection Principle, as a parasitoid develops inside a host it is conditioned visually and olfactorily, which enables the adult parasitoid to locate the same type of host in which to lay its eggs (Craighead, 1921; Smith \& Cornell, 1979; Davis \& Stamps, 2004). Little is known about conditioning and host selection in parasitoids of muscoid flies; however, in Trichopria nigra (Nees) (Hymenoptera: Diapriidae), a pupal endoparasitoid of several common species of flies, the host in which the female parasitoid is reared has a significant effect on their host-seeking behaviour and oviposition, with approximately twice as many females choosing their natal host over a non-natal host (Ferrero, 2008). In addition, (b) laboratory data on fecundity, number of adult progeny, host-induced mortality and sex ratio of $S$. cameroni reared on $C$. capitata are acceptable (Pérez-Hinarejos \& Beitia, 2008; Tormos, 2010, 2014).

Recently, problems caused by $M$. domestica in animal breeding facilities in the region of Valencia (Spain) (authors' pers. observ.) led us to determine the effectiveness of $S$. cameroni, reared for several generations on $C$. capitata pupae in parasitizing $M$. domestica pupae. Little is known about the effects of the host in which Spalangia is reared on its subsequent choice of host (Mandeville \& Mullen, 1990); however, our results demonstrate that a parasitoid reared for many generations on $C$. capitata is a more effective parasite of $M$. domestica. Measures of biotic potential, such as realized fecundity, number of pupae parasitized and number adult progeny emerging, were higher when freeze-killed pupae of $M$. domestica were used as hosts for $S$. cameroni than those of $C$. capitata. The sex ratio of the parasitoids emerging from both hosts was almost the same and the incidence of superparasitism was higher when $M$. domestica was the host. The higher level of parasitism of the house fly could be due to the greater size of $M$. domestica pupae or other characteristics (for example odour), making them appear more beneficial or attractive to ovipositing females of S. cameroni (King, 2002; Machtinger \& Geden, 2015).

Regarding the use of $S$. cameroni obtained from pupae of $C$. capitata for controlling $M$. domestica we have to take into account the possibility of natal conditioning when this parasite is used as a biocontrol agent where Mediterranean 
fruit fly and the house fly coexist. In this case, as stated by Mandeville (1988) for Muscidifurax zaraptor Kogan and Legner (Hymenoptera, Pteromalidae) parasitizing $M$. domestica or Fannia canicularis (L.) "Parasitoid ovipositional experience on one host or the other significantly biased subsequent host species preference in favor of the familiar host" and Ferrero (2008) for T. nigra "this species can even be conditioned to favor a host on which it cannot develop [house fly (Geden \& Moon, 2009)]". A postemergence conditioning of $S$. cameroni $(48 \mathrm{~h}$ on pupae of M. domestica), might possibly enhance its effectiveness in terms of host searching and parasitism. Adult conditioning of muscoid parasitoids is reported by Mandeville \& Mullens (1990). In their study, the strong innate preference of $M$. zaraptor for house fly over $F$. canicularis pupae shifted in favour of the latter species after two days of ovipositing on the latter. This shift occurred in spite of the fact that $M$. zaraptor is substantially more successful when it parasitizes $M$. domestica than $F$. canicularis.

$S$. cameroni reared on $C$. capitata can be used, in inundative releases, for the biological control of fruit flies (agriculture) and house flies (livestock farming). Studies carried out on dairy and pig farms show that S. cameroni is effective in controlling $M$. domestica, as it can significantly reduce the numbers of house flies and decrease levels of discomfort (Skovgård \& Nachman, 2004). In addition, companies such as Productos Biológicos Perkins Ltda (http://perkinsltda.com.co/) have optimized protocols for the use of $S$. cameroni as a biocontrol agent and sell them commercially for use against flies present in feedlots, stables, amongst pasture cattle and in piggeries.

ACKNOWLEDGEMENTS. The authors are indebted to B. King (Northern Illinois University, USA), K. Floate (Lethbridge Research Centre, Canada), H. Skovgård (Aarhus University, Denmark) and K. Ogawa (Kochi University, Japan) for their comments and suggestions.

\section{REFERENCES}

Abrams L. 1976: Cestoids in battery-housed laying hens. $-J$. Sth Afr. Vet. Assoc. 47: 171-173.

Birkemoe T., Soleng A. \& AAK A. 2009: Biological control of Musca domestica and Stomoxys calcitrans by mass releases of the parasitoid Spalangia cameroni on two Norwegian pig farms. - BioControl 54: 425-436.

Bruce W.N. \& Decker G.C. 1958: The relationship of stable fly (Stomoxys calcitrans) abundance to milk production in dairy cattle. - J. Econ. Entomol. 51: 269-274.

Campbell J.B., Berry I.L., Boxler D.J., Davis R.L., Clanton D.C. \& Deutscher G.H. 1987: Effects of stable flies (Diptera: Muscidae) on weight gain and feed efficiency of feedlot cattle. - J. Econ. Entomol. 80: 117-119.

CRAIGHEAD F.C. 1921: Hopkins host-selection principle as related to certain Cerambycid beetles. - J. Agric. Res. 22: 189-220.

Crespo D.C., Lecuona R.E. \& Hogssette J.A. 1998: Biological control: an important in integrated management of Musca domestica (Diptera: Muscidae) incaged-layer poultry houses in Buenos Aires, Argentina. - Biolol. Contr. 13: 16-24.

Chakrabarti S., King D.J., Cardona C.J. \& Gerry A.C. 2008: Persistence of exotic Newcastle disease virus (ENDV) in laboratory infected Musca domestica and Fannia canicularis. - Avian Dis. 52: 375-379.

Davis J.M. \& Stamps J.A. 2004: The effect of natal experience on habitat preferences. - Trends Ecol. Evol. 19: 411-416.

Falcó J.V., Garzón-Luque E., Pérez-Hinarejos M., Tarazona I., Malagón J. \& Beitia F. 2006: Two native pupal parasitoids of Ceratitis capitata (Diptera, Tephritidae) found in Spain. IOBC/WPRS Bull. 29: 71-74.

Ferrero K.M. 2008: Life History, Host Choice and Behavioral Plasticity of Trichopria nigra, (Hymenoptera: Diapriidae), a Parasitoid of Higher Diptera. MSc. Thesis, University of Florida, $118 \mathrm{pp}$.

Geden C.J. \& Hogsette J.A. 2006: Suppression of house flies (Diptera: Muscidae) in Florida poultry houses by sustained releases of Muscidifurax raptorellus and Spalangia cameroni (Hymenoptera: Pteromalidae). — Environ. Entomol. 35: 7582.

Geden C.J. \& Kaufmann P.E. 2007: Development Spalangia cameroni and Muscidifurax raptor (Hymenoptera: Pteromalidae) on live house fly (Diptera: Muscidae) pupae and pupae killed by heat shock, irradiation and cold. - Environ. Entomol. 36: 34-39.

Geden C.J. \& Moon R.D. 2009: Host ranges of gregarious muscoid fly parasitoids: Muscidifurax raptorellus (Hymenoptera: Pteromalidae), Tachinaephagus zealandicus (Hymenoptera: Encyrtidae), and Trichoprianigra (Hymenoptera: Diapriidae). - Environ. Entomol. 38: 700-707.

Geden C.J., Smith L., Long S.J. \& Rutz D.A. 1992: Rapid deterioration of searching behavior, host destruction, and fecundity of the parasitoid Muscidifurax raptor (Hymenoptera: Pteromalidae) in culture. - Ann. Entomol. Soc. Am. 85: 179-187.

Kaufman P.E. \& Geden C.J. 2009: Development of Spalangia cameroni and Muscidifurax raptor (Hymenoptera: Pteromalidae) on live and freeze-killed house fly (Diptera: Muscidae) pupae. - Fla Entomol. 92: 492-496.

Kaufman P.E., Long S.J. \& Rutz D.A. 2001: Impact of exposure length and pupal source on Muscidifurax raptorellus and Nassonia vitripennis (Hymenoptera: Pteromalidae) parasitism in a New York poultry facility. - J. Econ. Entomol. 94: 998-1003.

KING B.H. 2002: Offspring sex ratio and number in response to proportion of host sizes and ages in the parasitoid wasp Spalangia cameroni (Hymenoptera: Pteromalidae). — Environ. Entomol. 31: 505-508.

Machtinger E.T. \& Geden C.J. 2015: Comparison of the olfactory preferences of four of filth fly pupal parasitoid species (Hymenoptera: Pteromalidae) for hosts in equine and bovine manure. - Environ. Entomol. 44: 1417-1424.

Mandeville D. 1988: Host Preference, Fecundity, and Longevity of Muscidifurax zaraptor Kogan and Legner (Hymenoptera: Pteromalidae) Influenced by Musca domestica $L$. and Fannia canicularis (L.) (Diptera: Muscidae), with Notes on Parasitism by Spalangia spp. (Hymenoptera: Pteromalidae) in the Field. $\mathrm{PhD}$ Thesis, University of California, Riverside, $116 \mathrm{pp}$.

Mandeville J.D. \& Mullens B.A. 1990: Host preference and learning in Muscidifurax zaraptor (Hymenoptera: Pteromalidae). - Ann. Entomol. Soc. Am. 83: 1203-1209.

MiLuSHev I. 1978: Role of flies in the epizootiology of coccidiosis in poultry. - Vet.-Med. Nauki 15: 26-29.

Morgan P.B. \& Patterson R.S. 1990: Efficiency of target formulations of pesticides plus augmentative releases of Spalangia endius Walker (Hymenoptera: Pteromalidae) to suppress populations of Musca domestica L. (Diptera: Muscidae) at poultry ranches in the southeastern United States. In Rutz D.A. \& Patterson R.S. (eds): Biocontrol of Arthropods Affecting Livestock and Poultry. Westview Press, Boulder, CO, pp. 69-78. 
Ogawa K., Ito K., Fukuda T., Tebayashi S. \& Arakawa R. 2012: Host suitability of house fly, Musca domestica (Diptera: Muscidae), pupae killed by high or low temperature treatment for a parastoid, Spalangia endius (Hymenoptera: Pteromalidae). Scientific World J. 2012: Article ID 214907, 4 pp.

Pérez-Hinarejos M. \& Beitia F. 2008: Parasitism of Spalangia cameroni (Hymenoptera: Pteromalidae), an idiobiont parasitoid on pupae of Ceratitis capitata (Diptera: Tephritidae). IOBC/WPRS Bull. 38: 130-133.

Rosef O. \& Kapperud G. 1983: House flies (Musca domestica) as possible vectors of Campylobacter fetus subsp. jejuni. - Appl. Environ. Microbiol. 45: 381-383.

SKOVGÅR H. 2006: Search efficiency of Spalangia cameroni and Muscidifurax raptor on Musca domestica pupae in dairy cattle farms in Denmark. - BioControl 51: 49-64.

Skovg̊̊rd H. \& Nachman G. 2004: Biological control of house fly Musca domestica and stable flies Stomoxys calcitrans (Diptera: Muscidae) by means of inundative releases of Spalangia cameroni (Hymenoptera: Pteromalidae). - Bull. Entomol. Res. 94: 555-567.

SMith M.A. \& CoRnell H.V. 1979: Hopkins host-selection in $\mathrm{Na}$ sonia vitripennis and its implications for sympatric speciation. - Anim. Behav. 27: 365-370.
Steenberg T., Skovgård H., Kalsbeek V. \& Jespersen J.B. 2001: Microbial and biological control of flies in stables. - DJFrapport (Markbrug) No. 49, pp. 91-94.

Tormos J., Beitia F., Böckmann E.A. \& Asís J.D. 2009: The preimaginal stages and development of Spalangia cameroni Perkins (Hymenoptera: Pteromalidae) on Ceratitis capitata (Wiedemann) (Diptera: Tephritidae). - Micron 40: 646-658.

Tormos J., Beitia F., Alonso M., Asís J.D. \& Gayubo F. 2010: Assessment of Ceratitis capitata (Diptera, Tephritidae) pupae killed by heat or cold as hosts for rearing Spalangia cameroni (Hymenoptera: Pteromalidae). — Ann. Appl. Biol. 16: 179185.

Tormos J., SABater-Muñoz B., Asís J.D. \& Beitia F. 2014: Validation of a methodology for rearing Spalangia cameroni (Hymenoptera: Pteromalidae) on Ceratitis capitata (Diptera: Tephritidae). - Can. Entomol. 146: 676-683.

Wanaratana A., Amonsin A., Chaising S., Panyin J., SasipreeYAJAN J. \& PAKPINYO S. 2013: Experimental assessment of house flies as vectors in avian influenza subtype H5N1 transmission in chickens. - Avian Dis. 57: 266-272.

Received May 19, 2015; revised and accepted November 12, 2015 Published online January 14, 2016 